\title{
Fusão do novo coronavírus (SARS-CoV-2) em células humanas: papel da Enzima Conversora de Angiotensina 2 (ECA2) e da Serina Protease Transmembranar 2 (TMPRSS2)
}

\author{
Igor Gomes de Araújo'
}

Arlandia Cristina Lima Nobre de Morais $^{2}$

\section{RESUMO}

Existem vários tipos de coronavírus, contudo sabe-se que três tipos são responsáveis pela infecção respiratória grave em seres humanos: SARS-CoV (SARS), Mers-CoV (MERS) e o novo SARS-CoV-2. A transmissão ocorre pela contaminação de fluidos salivares, partículas retidas sobre o ar pelo espirro ou tosse, contato próximo com pessoas e superfícies contaminadas. E os primeiros sintomas ocorrem entre 2 à 14 dias, chamado de período de incubação viral. Por se tratar de uma nova patologia, os sintomas graves e anormalidades desafiam a ciência. Há várias possibilidades farmacológicas em fases de testes. Há relevância em desvendar estudos sobre a Enzima Conversora de Angiotensina 2 (ECA2) e a Protease Transmembranar, a serina 2 (TMPRSS2) no SARS-CoV-2, alvos enzimáticos com perspectivas farmacológicas para o tratamento da COVID-19. Partindo de tal premissa, temse que produtos farmacêuticos com alvo na inibição da ECA2 e TMPRSS2 apresentam expectativas promissoras no tratamento do SARS-CoV-2. Afinal, a inibição da ECA2, enzima localizada nos principais órgãos onde a doença se prolifera, possui potencial em diminuir liberação de citocinas pró-inflamatórias. Enquanto a inibição da TMPRSS2 impediria a entrada do vírus nas células humanas a nível do trato respiratório superior.

\section{ABSTRACT}

There are several types of coronavirus, however it is known that three types are responsible for severe respiratory infection in humans: SARS-CoV (SARS), Mers-CoV (MERS) and the new SARS-CoV-2. Transmission occurs through contamination of salivary fluids, particles retained in the air by sneezing or coughing, close contact with contaminated people and surfaces. And the first symptoms occur between 2 to 14 days, called the viral incubation period. Because it is a new pathology, severe symptoms and abnormalities defy science. There are several pharmacological possibilities in testing phases. It is relevant to unveil studies on

\footnotetext{
${ }^{1}$ Graduando em farmácia. Universidade de Fortaleza, Avenida Washington Soares, 1321, Edson Queiroz, 60811-905, Fortaleza, Ceará, Brasil. E-mail: gomes.igor1996@gmail.com

${ }^{2}$ Farmacêutica, Doutora em Farmacologia, Universidade de Fortaleza, Avenida Washington Soares, 1321, Edson Queiroz, 60811-905, Fortaleza, Ceará, Brasil.
} 
Angiotensin-Converting Enzyme 2 (ECA2) and Transmembrane Protease, serine 2 (TMPRSS2) in SARS-CoV-2, enzymatic targets with pharmacological perspectives for the treatment of COVID-19. Based on this premise, pharmaceutical products targeting ACE2, an enzyme located in the mair inflammatory cytokines. While inhibition of TMPRSS2 would prevent the virus from entering human cells at the level of the upper respiratory tract.

Palavras-chave: SARS-CoV-2; COVID-19; novo coronavírus; ECA2; TMPRSS2.

Keywords: SARS-CoV-2; COVID-19; new coronavirus; ECA2; TMPRSS2.

O coronavírus foi isolado pela primeira vez em 1937 e em 31 de dezembro de 2019 foi notificado o primeiro caso do SARS-CoV-2, na província de Wuhan, na China. Conhecido como o novo coronavírus, causador da doença COVID-19 [1]. A Organização Mundial de Saúde (OMS), declarou pandemia no dia 11 de março de 2020, estabelecendo Emergência de Saúde Pública de Importância Internacional (ESPII), considerado alerta máximo [2].

Existem vários tipos de coronavírus, contudo sabe-se que três tipos são responsáveis pela infecção respiratória grave em seres humanos: SARS-CoV (SARS) Mers-CoV (MERS) e o novo SARS-CoV-2 [3]. Trata-se de um vírus de RNA de fita simples, apresentando simetria de $88 \%$ a $89 \%$ com tipos de SARS oriundos de morcegos, o morcego-SL-CoVZC45 (número de acesso ao GenBank MG772933 1) e morce MG772933.1) e (Acesso [isso, os estudos de Chen et al., (2020), sobre um sequenciamento genético viral concluíram que ocorreu um "spillover", ou seja, um adaptação e migração de uma espécie para outra [5].

A transmissão ocorre pela contaminação de fluidos salivares, partículas retidas sobre $o$ ar pelo espirro ou tosse, contato próximo com pessoas e superfícies contaminadas. E os primeiros sintomas ocorem entre 2 a 14 dias, chamado de período de incubação viral [1]

No Brasil, a atualização do dia 04 de maio de 2020, registrou no total 107.780 casos confirmados, 45.815 curados, 54.644 em acompanhamento, 7.321 óbitos e 1.427 óbitos em investigação. Os maiores casos ocorrem em São Paulo com 32.187 casos confirmados, 2.654 mortes, em seguida, Rio de Janeiro com 11.721 casos confirmados e 1.065 mortes [6].

Por se tratar de uma nova patologia, os sintomas graves e anormalidades desafiam a ciência. Estando intensamente demonstrado a manifestação clínica envolvendo o trato respiratório inferior, e especulando a implicação em outros órgãos. Ressaltase a maior vulnerabilidade em pessoas portadoras de doenças crônico-degenerativas, contudo não omitindo a possibilidade de acometimento em pessoas consideradas saudáveis, pela alta capacidade de infecção da COVID-19

O diagnóstico é realizado através da detecção do RNA do vírus por técnica em biologia molecular (RT-PCR), anticorpos IgM e lgG, através de colunas cromatográficas (testes rápidos qualitativos e quantitativos) e sorológicos [7].

O primeiro sequenciamento genético do SARSCoV-2, no Brasil, analisou nove mutações em comparação com a cepa original de Wuhan na China, e isto incita um comafio ainda maior para pesquisadores desenvolverem tratamentos eficazes [8]

Há várias possibilidades farmacológicas em fases de testes: Pirfenidona, ASC-09/ritonavir, Darunavir/ Ritonavir/Lopinavir ou Ritonavir/Lopinavir e Interferon beta, Sarilumab, Oseltamivir e Arbidol (umifenovir). Do qual Cloroquina/Hidroxicloroquina bloquearam a entrada do SARS-CoV-2 na célula e Remdesivir desmonstraram atividades promissoras em testes in-vitro $[1,9,10]$

O medicamento Nitazoxanide também em estudo já apresentou atividade inibidora especificamente da expressão protéica N viral, in vitro contra o MERS-CoV e outros coronavírus. Inibindo também citocinas próinflamatórias como a interleucina 6 em camundongos [11].

Há relevância em desvendar estudos sobre a Enzima Conversora de Angiotensina 2 (ECA2) e Protease alvos enzimáticos com perspectivas farmacológicas para o tratamento da COVID-19. Cobicistat, Cloroquina/Hidroxicloroquina, Remdesivir,
O sistema renina-angiotensina-aldosterona (SRAA) apresenta importantes funcões fisiológicas, como a regulação da pressão arterial, balanço hídrico e de sódio. Ocorrendo alguma falha nestas funções a renina cliva o angiotensinogênio (AGT) originado no fígado, produzindo angiotensina I (ANG I). A enzima conversora da angiotensina (ECA) converte angiotensina I em angiotensina II, potente vasoconstritora. Por sua vez, estimula a síntese da aldosterona pela supra renal que regula o balanço hidroeletrolítico, retendo sódio elevando a pressão arterial [12]

A angiotensina II, possui papel importante neste sistema, ao atuar em seus receptores a AT1 e AT2. Este peptídeo é capaz de aumentar a produção de citocinas inflamatórias, interleucinas 1 e 6 (IL) e fator de necrose tumoral (TNF), que acomete a função cardíaca. Portanto, sabe-se que este peptídeo possui função considerável na insuficiência cardíaca potencializando consequências a nível miocárdico. Ademais acarreta produção de radicais livres potencializando reações inflamatórias nos vasos [13].

Bregagnollo et al. [14] afirmaram haver evidências de que tecidos como o cérebro, hipófise, vasos sanguíneos, coração, rins e glândulas adrenais apresentam todos os componentes do SRAA, possuindo propriedade em originar ANG II local. Havendo variações a depender da quantidade de renina liberada [13].

Outro tecido alvo é o endotélio dos vasos dos pulmões onde há preeminência da ECA [15].

Pesquisadores da Universidade São Paulo (USP), do departamento de ciências farmacêuticas, publicaram uma hipótese que o gene ACE-2 possibilita a infecção pelo coronavírus em células pulmonares e que este mesmo gene está correlacionado com os sintomas mais graves da doença por portadores de doenças crônicas. Já se sabia que o SARS causador da epidemia em 2003 tinha prefer̂ncia por essa proténa. Este mesmo genech de ACE-2 orienta a produção da ECA2 O SARS-CoV-2 ao se ligar neste possível receptor utiliza de uma importante protease como a TMPRSS2 que realiza uma clivagem no C-terminal da ACE2, manifestada primordialmente no tecido pulmonar [16].

Esta Protease Transmembranar, a serina (TMPRSS2), predominante no epitélio de células pulmonares a nivel de trato respiratório superior, possui função en clivar glicoproternas importantes da estr funçăo em clivar glicoproteinas importantes da estrutura do novo coronavirus, particulamente a proteina spike ou s, possibilitando a ligação e proporcionando a entrada do virus na célula humana. Os estudos não estão muito claros em humanos, ao mesmo tempo sabe-se que inibidores da TMPRSS2 são potenciais alvos farmacológicos contra o rus H1N1 [17,18].

Partindo de tal premissa, tem-se que produtos farmacêuticos com alvo na inibição da ECA2 e TMPRSS2 apresentam expectativas promissoras no tratamento do SARS-CoV-2. Afinal, a inibição da ECA2, enzima localizada nos principais órgãos onde a doença se prolifera, possui potencial em diminuir liberação de citocinas próinflamatórias. Enquanto a inibição da TMPRSS2 impediria a entrada do vírus nas células humanas a nível do trato respiratório superior.

\section{REFERÊNCIAS}

1. Wang Chen, Horby Peter W, Hayden Frederick G, Gao George F. A novel coronavirus outbreak of globa health concern. The Lancet. 2020:395(10223):470473. doi.org/10.1016/50140-6736(20)30185-9

2. World Health Organization. Pneumonia of unknown cause - China: disease outbreak news. Geneva: World Health Organization. 2020 (accessed 2020 Apr 30) Available at: https://www.who.int/csr/don/05-january2020-pneumonia-of-unkown-cause-china/en/

3. Lu H, Stratton CW, Tang YW. Outbreak of pneumonia of unknown etiology in Wuhan China: the mystery and the miracle. J Med Virol. 2020;92:401-402. (accessed 2020 May 02). doi:10.1002/jmv.25678

4. Paules $\mathrm{Cl}$, Marston HD, Fauci AS. Coronavirus infections-more than just the common cold. JAMA. 2020:323(8):707-708. doi:10.1001/jama.2020.0757

5. Wang D, Hu B, Hu C, Zhu F, Liu X, Zhang J. et a Clinical Characteristics of 138 Hospitalized Patients With 2019 Novel Coronavirus-Infected Pneumonia in Wuhan, China. JAMA. 2020;323(11):1061ه1069. doi:10.1001/jama.2020.1585

6. Johns Hopkins University Coronavirus COVID-19 Global Cases by Johns Hopkins CSSE [Internet]. Johns Hopkins University; 2020 (accessed 2020 
May 08] Available at: https://gisanddata.maps. arcgis.com/apps/opsdashboard/index.html\#/ bda7594740fd40299423467b48e9ecf6

7. Croda JHR, Garcia LP. Resposta imediata da Vigilância em Saúde à epidemia da COVID-19. Epidemiol. Serv. Saúde 2020;29(1):e2020002. doi: 10.5123/S167949742020000100021.

8. Brasil. Ministério da Saúde. Portaria MS/GM n 188, de 3 de fevereiro de 2020. Declara Emergência em Saúde Pública de importância Nacional (ESPIN) em decorrência da Infecção Humana pelo novo Coronavírus (2019nCoV) [Internet]. Diário Oficial da União, Brasília (DF), 2020 fev 4;Seção Extra:1. (acessado 2020 Mai 02). Disponível em: http://portalarquivos.saude.gov. br/images/pdf/2020/April/06/2020-04-06---BE7--Boletim-Especial-do-COE---Atualizacao-da-Avaliacaode-Risco.pdf

9. Centers for Disease Control and Prevention. Coronavirus Disease 2019 (COVID-19). How to Protect Yourself and Others. 2019 (accessed 2020 May 01). Available at:https://www.cdc.gov/coronavirus/2019ncov/index.html/

10. Anderson RM, Heesterbeek $H$, Klinkenberg $D$, Hollingsworth TD. How will country-based mitigation measures influence the course of the COVID-19 epidemic? Lancet 2020; 395(10228): 931-4. doi. org/10.1016/50140-6736(20)30567-5

11. Liu Y, Gayle AA, Wilder-Smith A, Rocklöv J. The reproductive number of COVID-19 is higher compared to SARS coronavirus. J Travel Med 2020; 27(2): 1-4. doi.org/10.1093/jtm/taaa021

12. The Novel Coronavirus Pneumonia Emergency Response Epidemiology Team. The Epidemiological Characteristics of an Outbreak of 2019 Novel Coronavirus Diseases (COVID-19) - China, 2020[J]. China CDC Weekly. 2020;2(8):113-122. (accessed 2020 May 03). Available at: http://weekly.chinacdc. cn/en/article/id/e53946e2-c6c4-41 e9-9a9bfea8db1a8f51

13. Brasil. Ministério da Saúde. Boletim COE COVID-19 Centro de Operações de Emergência em Saúde
Pública. Doença pelo Coronavírus 2019. n 12, de 19 de abril de 2020. Especial Vigilância Epidemiológica Laboratorial. 2020; Semana Epidemioógica: 17 (1925/04). (acessado 2020 Mai 02). Disponível em:http:// portalarquivos.saude.gov.br/images/pdf/2020/ April/19/BE12-Boletim-do-COE.pdf

14. Ganem F, Mendes FM, Oliveira SB, Porto VBG, Araujo $\mathrm{W}$, Nakaya $\mathrm{H}$ et al. The impact of early social distancing at COVID-19 Outbreak in the largest Metropolitan Area of Brazil. medRxiv. 2020; doi. org/10.1101/2020.04.06.20055103

15. Markel H, Lipman HB, Navarro JA, Sloan UM, Michalsen $J R$, Stern AM et al. Nonpharmaceutical Interventions Implemented by US Cities During the 1918-1919 Influenza Pandemic. JAMA. 2007;298(6):644-654. (accessed 2020 May 02). Available at: doi:10.1001/ jama.298.6.644

Telefone: (34) 3230-9432 